\title{
A novel, highly efficient $\beta$-glucosidase with a cellulose-binding domain: characterization and properties of native and recombinant proteins
}

\author{
J. A. Méndez-Líter, J. Gil-Muñoz, M. Nieto-Domínguez, J. Barriuso, L. I. de Eugenio and M. J. Martínez* ${ }^{\circ}$
}

\begin{abstract}
Background: Cellulose, the most abundant biopolymer on earth, is an alternative for fossil fuels as a renewable feedstock for the production of second-generation biofuels and other chemicals. The discovery of novel, highly efficient $\beta$-glucosidases remains as one of the major bottlenecks for cellulose degradation. In this context, the ascomycete Talaromyces amestolkiae, isolated from cereal samples, has been studied as a promising source for these enzymes.

Results: $B G L-2$ is the major $\beta$-glucosidase secreted by this fungus in the presence of cellulosic inductors. This enzyme possesses a CBD (Cellulose Binding Domain), an unusual feature among this type of proteins. Besides, when growing on cellulose, the fungus produced two different $b g /-2$ mRNAs that were cloned and expressed in Pichia pastoris. A complete recombinant protein (BGL-2*) and its truncated form, lacking CBD (BGL-2T*), have been purified, characterized and compared with the native enzyme (BGL-2). The three BGL-2 forms studied are highly stable in a wide $\mathrm{pH}$ range, but BGL-2T* showed an improved thermal stability at $50^{\circ} \mathrm{C}$ after $72 \mathrm{~h}$. Using $p$-nitrophenyl- $\beta$-Dglucopyranoside as a substrate, the steady-state kinetic characterization of the three proteins showed a similar $K_{m}$ and $k_{\text {cat }}$ for BGL-2 and BGL-2* , while the truncated protein displayed a threefold higher value for $k_{\text {cat }}$. All tested BGL-2 enzymes were as well highly efficient using cellobiose and other short oligosaccharides as a substrate. In view of biotechnological applications, the recombinant T. amestolkiae enzymes in saccharification of brewers' spent grain were studied, being comparable to commercial $\beta$-glucosidase cocktails.

Conclusion: A new $\beta$-glucosidase from T. amestolkiae has been studied. The enzyme, containing a functional CBD, has been expressed in P. pastoris. The comparative analyses of the native protein and its recombinant forms, with and without CBD, suggest that they could be suitable tools for valorization of lignocellulosic biomass.
\end{abstract}

Keywords: Fungi, Glycosyl hydrolases, Pichia pastoris, Carbohydrate binding modules, Saccharification, Brewers spent grain

\section{Background}

The current need of finding sustainable and renewable energy sources is making the degradation of lignocellulosic biomass to produce second-generation biofuels a blooming subject, since they may represent a viable alternative to fossil fuels $[1,2]$. Lignocellulosic biomass

*Correspondence: mjmartinez@cib.csic.es

Department of Environmental Biology, Centro de Investigaciones

Biológicas, CSIC, Ramiro de Maeztu 9, 28040 Madrid, Spain degradation requires different steps: (i) pretreatment to improve polysaccharide accessibility, (ii) enzymatic hydrolysis of cellulose and hemicellulose and (iii) fermentation of free monosaccharides to ethanol [3]. Steam explosion is the most common pretreatment method used to disrupt plant cell wall components. Although very effective, the use of high pressures and temperatures generates undesirable compounds from sugars and lignin, which produce negative effects on enzymatic hydrolysis and fermentation [4]. 
The plant cell wall consists of three major components, whose proportions depend on the source of the lignocellulosic biomass: cellulose, hemicellulose, and lignin [5]. Nowadays, commercial enzymatic cocktails used for hydrolysis of lignocellulosic biomass contain cellulases, hemicellulases, and other complementary enzymes that facilitate the complete degradation of plant cell wall. Cellulose, the most abundant polymer on earth, is a polysaccharide composed of long linear chains of D-glucose linked by $\beta-(1,4)$ glycosidic bonds. Besides being used for biofuels production, this polysaccharide is basic to a multitude of industrial processes like paper pulp and chemicals production [5]. Cellulose is enzymatically hydrolyzed by the combined action of endoglucanases (EGs) (EC 3.2.1.4), cellobiohydrolases (CBHs) (EC 3.2.1.91), and $\beta$-glucosidases (BGLs) (EC 3.2.1.21) [6]. The effect of CBHs and EGs on cellulose generates short soluble oligosaccharides, which are converted into glucose by $\beta$-glucosidases. These enzymes are members of the glycoside hydrolases (GHs) family and attack polysaccharides like cellulose in a relatively inefficient way, as their glycosidic bonds are often inaccessible to the active site of the enzymes. This is due to the low solubility of these polysaccharides and/or to their crystalline structures. A wide variety of glycoside hydrolases that degrade such insoluble substrates have structural domains known as carbohydrate binding modules (CBMs), for example, cellulose binding domains (CBDs), which are useful for the recognition and attachment of GHs to their substrates [7].

Although the synergistic action of all the cellulolytic activities is required to fully degrade cellulose, $\beta$-glucosidases are considered as the key enzymes for this process as they are indispensible for releasing free glucose. $\beta$-glucosidases are generally found in little proportion in commercial preparations, usually produced from Trichoderma and Aspergillus species [8]. Hence, many studies are focusing on finding robust $\beta$-glucosidases, since enzyme cocktails must be supplemented with this activity to increase the efficiency of cellulose saccharification [8].

Commercial $\beta$-glucosidases are typically obtained from filamentous fungi because fungal enzymes usually have a higher catalytic productivity/efficiency than other microorganisms. In the last years, the high cellulolytic potential of various Penicillium species and its perfect states, Talaromyces or Eupenicillium, has been reported $[9,10]$. In this sense, a recent work revealed that $T$. amestolkiae produces several $\beta$-glucosidases in the presence of different carbon sources [11]. Here we report the purification, heterologous expression and biochemical characterization of a $\beta$-glucosidase produced by this fungus in the presence of cellulosic substrates. In addition, we evaluated its role in saccharification of brewers spent grain.

\section{Results and discussion}

Production, purification and properties of native BGL-2

Talaromyces amestolkiae has been recently described as a fungus producing a wide variety of cellulases. Different types of these enzymes were secreted as a function of the available carbon source. On cellulosic substrates, a $\beta$-glucosidase was abundantly produced. In this work, this novel $\beta$-glucosidase has been purified from 8-dayold T. amestolkiae cultures growing in Mandels medium containing 1\% Avicel, when maximal BGL activity levels were reached. For purification, three consecutive chromatographic steps were needed. The filtered, concentrated and dialyzed crude was first loaded on a HiTrap Capto Adhere cartridge, a strong anion exchanger with multimodal functionality. Two peaks containing BGL activity were recovered indicating that, in these conditions, the fungus produced at least two $\beta$-glucosidases. This finding agrees with the results from a proteomic analysis of the secretome released in Avicel cultures of this fungus, which disclosed the production of different $\beta$-glucosidases [11]. Proteins from peak 2 (containing around $79 \%$ of initial BGL activity), were concentrated and loaded in a Mono Q column. After this chromatographic stage, again, two peaks with BGL activity were separated. The first peak, containing $80 \%$ of total BGL activity of this step, was concentrated and subjected to size exclusion chromatography in Superdex $75 \mathrm{HR}$ $10 / 30$ to complete the protein purification. This protein, denominated as BGL-2, was purified around fourfold with a final yield of $6.3 \%$ (Table 1).

The molecular mass of BGL-2, estimated by SDSPAGE, was around $100 \mathrm{kDa}$ (Fig. 1a). Besides, although enzymatic $N$ - and $O$-deglycosylation of BGL-2 did not alter its molecular mass, PAS staining showed a purple BGL-2 band, indicating its glycoprotein nature (Fig. 1b). This result suggests that BGL-2 may be $O$-glycosylated since enzymatic $O$-deglycosylation is not very efficient for fungal glycoproteins due to the heterogeneity of this post-translational modification, oppositely to $N$-deglycosylases that are usually very efficient because $N$-glycosylation is evolutionary conserved [12].

\section{Sequence analysis and homology modeling of BGL-2}

The peptide mass fingerprinting of this protein evidenced internal peptides that showed high similarities with a hypothetical $\beta$-glucosidase (XP_002149046) from Talaromyces marneffei ATCC 18224. Using TBLASTN, the sequence of these peptides was used to identify the $b g l 2$ gene in the genome of T. amestolkiae, deposited in the NCBI database with accession number of MIKG00000000.

Analysis of $b g l-2$ gene indicated that this protein belongs to the GH3 family. Surprisingly, a sequence 
Table 1 Purification yield of native and recombinant BGL-2 isoforms

\begin{tabular}{|c|c|c|c|c|}
\hline Step & Total protein (mg) & Total activity (U) & Specific activity (U/mg) & Yield (\%) \\
\hline \multicolumn{5}{|l|}{$B G L-2$} \\
\hline Crude extracts & 53.4 & 1039.7 & 19.5 & 100 \\
\hline HiTrap Capto Adhere & 15.8 & 795.6 & 50.4 & 76.5 \\
\hline Mono Q 5/50 & 7.6 & 596.4 & 78.5 & 57.3 \\
\hline Superdex 75 HR 10/30 & 0.8 & 66.1 & 82.6 & 6.3 \\
\hline \multicolumn{5}{|l|}{$B G L-2^{*}$} \\
\hline Crude extracts & 25.1 & 300.1 & 11.9 & 100 \\
\hline HiTrap Capto Adhere & 7.64 & 126.5 & 16.5 & 42.2 \\
\hline \multicolumn{5}{|l|}{$B G L-2 T^{*}$} \\
\hline Crude extracts & 19.9 & 436.1 & 21.8 & 100 \\
\hline HiTrap Capto Adhere & 3.6 & 128.8 & 35.4 & 29.5 \\
\hline
\end{tabular}

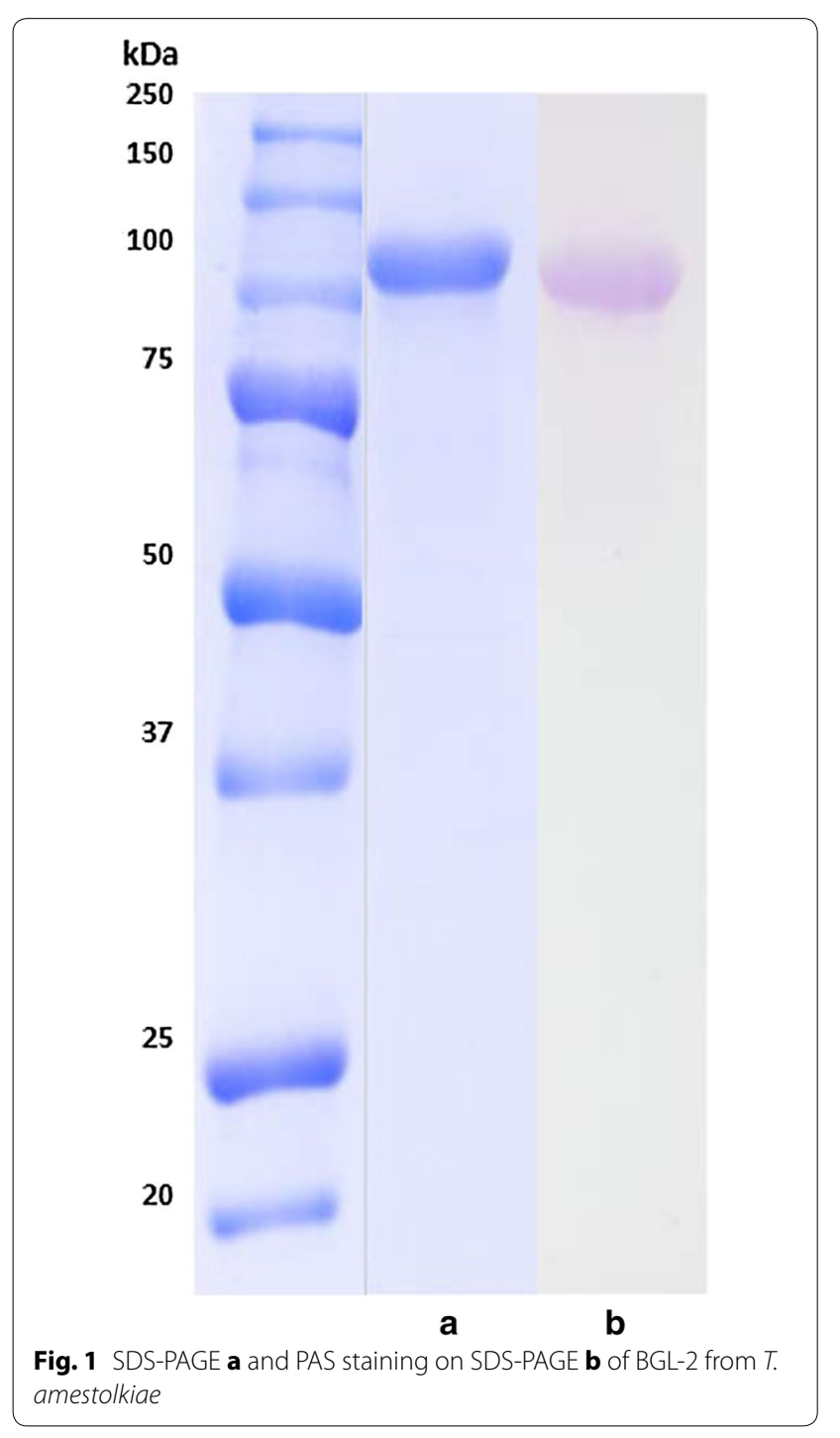

compatible with the presence of a CBD was found. This region is common in cellobiohydrolases and endoglucanases [13], but very rare in a $\beta$-glucosidase. The CBD was linked to the catalytic domain through a serine-threonine rich region that would act as a flexible connector between both regions, as reported for Trichoderma reesei cellobiohydrolase I [14]. The ability to bind cellulose has only been described for the $\beta$-glucosidase of Phanerochaete chrysosporium [15], which has a CBD in its N-terminal domain, but this enzyme was finally identified as a glucan-1,3- $\beta$ glucosidase [16], with much more activity on laminaribiose and laminarin than on cellobiose. Hence, $T$. amestolkiae BGL-2 is the first 1,4- $\beta$-glucosidase where a CBD has been characterized.

Intron and exon identification was performed by comparison with transcriptomic data from the most similar sequences (XM_002485083 and XM_002149010) using BlastN. It was concluded that $b g l 2$ gene is interrupted by three introns, with a sequence of $2460 \mathrm{bp}$, coding for 819 amino acids (GenBank Accession Number: KM393203). Intron prediction was confirmed after RNA extraction and cDNA production.

The information gathered in the databases on the crystal structures of fungal $\beta$-glucosidases from the GH3 family is very limited. Only four GH3 crystal structures are available in Protein Data Bank (PDB), three from Hypocrea jecorina (synonym of Trichoderma reesei) (4I8D, 3ZZ1 and 3ZYZ) [17] and one from Aspergillus aculeatus (4IIB) [18]. As in BGL-2, the catalytic domain of these proteins is divided into three subdomains: a $N$-terminal domain with $\operatorname{TIM}(\alpha / \beta) 8$ barrel form, a $C$-terminal domain with $\alpha / \beta$ sandwich, and a fibronectin III-like domain, with unknown role and possible implications in thermal stability $[18,19]$. The model 
structure of $T$. amestolkiae BGL-2 was obtained using structures $3 \mathrm{ZYZ}$ and 4I8D from PDB as templates, which showed an identity of $64.2 \%$. QMean value in both cases was -3 , indicating that the model was well adjusted to the experimental structures.

The CBD of BGL-2 was modeled separately since the fungal $\beta$-glucosidases of $H$. jecorina lack this domain. The model that best adjusted (QMean - 0.51) came from a $\mathrm{CBH}$ of this fungus (PDB:1CBH). Finally, the modeling of the linker between the catalytic domain and CBD was performed manually because there is no such crystallized structure deposited, probably due to its high flexibility (Fig. 2).

The BGL-2 CBD sequence was compared with CBMs reported for other cellulases using the protein-protein Blast database (BlastP), indicating that it belongs to family 1 (CBM1) since it had most of the conserved amino acids characteristic of this family (Fig. 3). With some of the best matches, a sequence alignment using T-coffee program was performed.

\section{Heterologous expression of $b g / 2$}

PCR fragments containing bgl2 cDNA obtained by reverse transcription were purified and cloned into pPIC9. Unexpectedly, two different sequences were obtained: one with the expected size for the fungal gene sequence after excision of the three predicted introns (2460 bp length) and another $65 \mathrm{bp}$ longer (2525 bp), which had retained the third intron, maybe due to an alternative or wrong RNA processing. Clones with this sequence will produce a truncated form of BGL-2 (without CBD) since this intron contains a stop codon upstream the CBD coding region. Thus, two constructs were isolated: I) a fragment that will produce a truncated form of $b g l 2$ without CBD, named BGL-2T**, with

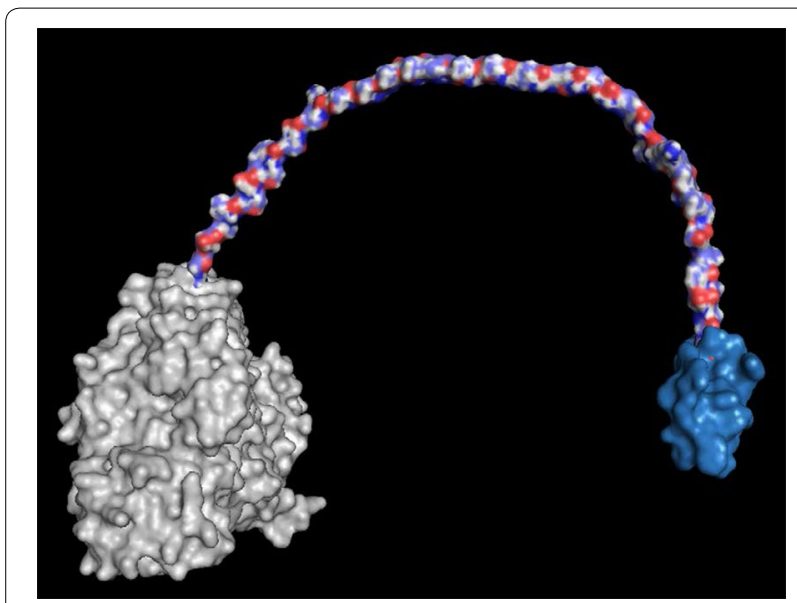

Fig. 2 Molecular surface model of BGL-2 from T. amestolkiae. The catalytic domain (grey), the connector (blue, red and white) and the CBD (blue) are depicted a coding sequence of $2202 \mathrm{bp}$ and 734 amino acids; and II), the fragment that will generate the complete form of bgl2, including the CBD, that will be named BGL-2*, with a coding sequence of $2460 \mathrm{bp}$ and 820 amino acids (Additional file 1: Figure S1). This misprocessing of mRNA in $b g l 2$ gene could be related to an alternative splicing phenomenon. In fact, alternative splicing mechanisms have been described in some cellobiohydrolases from $P$. chrysosporium, in which selective transcription of CBD occurs depending on the carbon source [20]. As other filamentous fungi, T. amestolkiae exhibits the property of expressing different isoforms of cellulases depending on the culture conditions or carbon sources.

The pPIC9 vectors containing both cDNA fragments encoding BGL-2 and its truncated form BGL-2T* were transformed into $P$. pastoris KM71 strain. Transformants selected in YNB-His medium were plated in YPM to detect $\beta$-glucosidase activity after MUG-agar incubation, as described in "Methods" section. The transformants that produced higher fluorescence were chosen as potential enzyme producers because they were able to hydrolyze MUG efficiently.

\section{Production of BGL-2* and BGL-2T* in Pichia pastoris and purification of the recombinant enzymes}

Figure 4 shows that recombinant $P$. pastoris yeast strains, which produce either the complete, or the truncated form of BGL-2, secreted higher $\beta$-glucosidase activity levels than T. amestolkiae growing in Mandels medium with Avicel as carbon source (fivefold and twofold, respectively). Although the time needed for optimal secretion was similar, the higher production levels and the few extracellular proteins secreted by $P$. pastoris strains facilitated its further purification.

Both recombinant proteins were purified in a single chromatographic step using a HiTrap Capto Adhere cartridge, with a yield of 42 and $29 \%$ for BGL-2* and BGL$2 \mathrm{~T}^{*}$, respectively, which represent an increased yield of sevenfold and fivefold compared with the native protein.

\section{Comparative properties of native and recombinant BGL-2 proteins}

Molecular mass of BGL-2, BGL-2* and BGL-2T* were studied by MALDI-TOF MS and size exclusion chromatography. All BGL-2 forms are monomeric enzymes, with an accurate molecular mass of $97.2,102.1$ and $80.8 \mathrm{kDa}$ for BGL-2, BGL-2* and BGL-2T*, respectively (Additional file 1: Figure S2). The differences found between theoretical $(83.1 \mathrm{kDa}$ for the complete enzymes and $74.4 \mathrm{kDa}$ for the truncated BGL-2) and empirical molecular masses can be attributed to protein glycosylation: $14.7 \%$, for BGL2, $18.7 \%$ for BGL-2* and $8 \%$ for BGL-2T*. It is noticeable that the truncated form without CBD is fairly less 


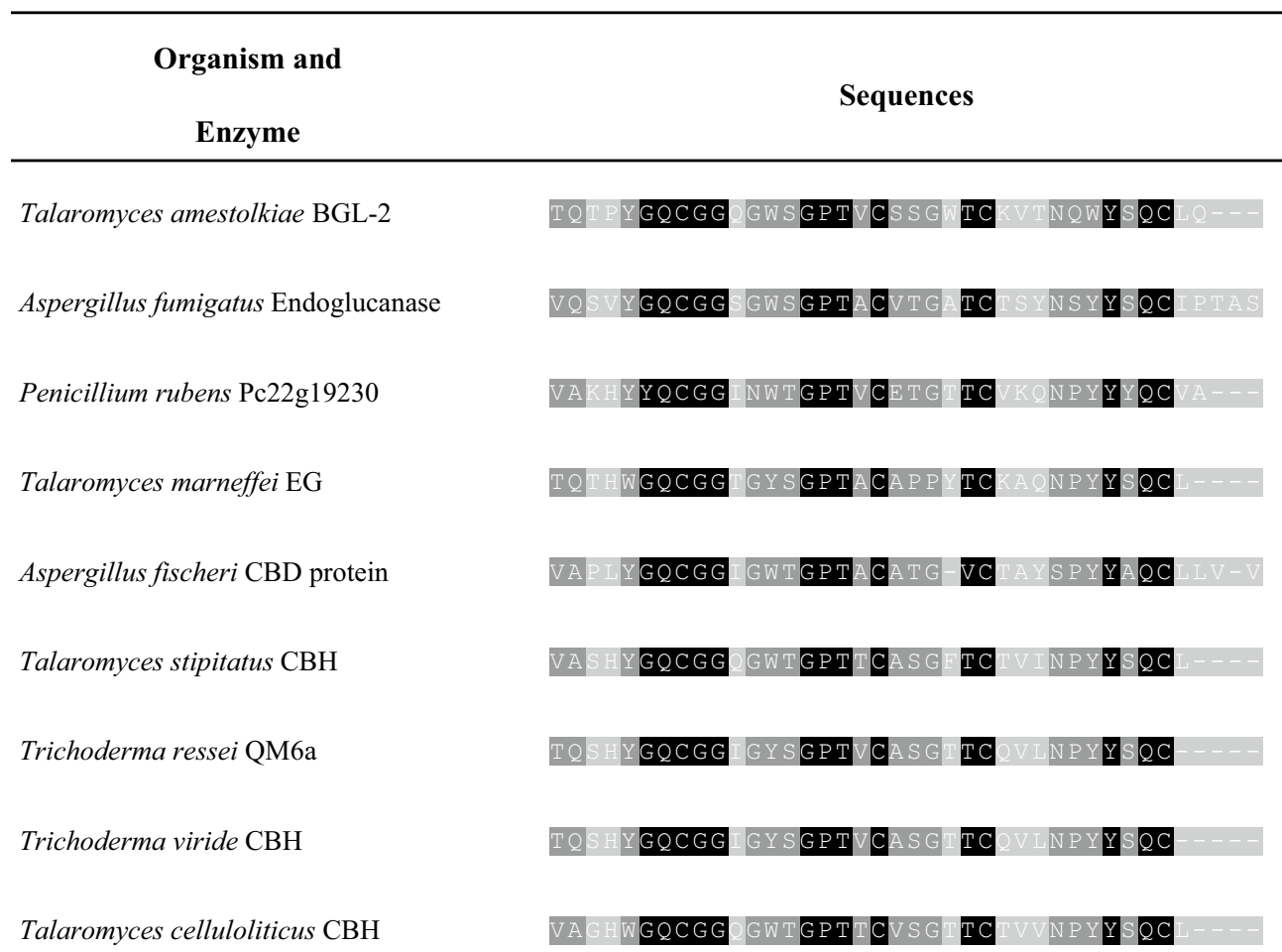

Fig. 3 Sequence alignment of the CBD region of T. amestolkiae BGL-2 with other CBDs reported in different fungal cellulases using the T-coffee alignment program. The accession numbers of the compared enzymes are: XP_748707.1 (A. fumigatus), XP_002565826.1 (P. rubens), XP_002152969.1 (T. marneffei), XP_001262453.1 (A. fischeri), and XP_002484839.1 (T. stipitatus), XP_006969224.1 (T. reesei), AAQ76092.1 (T. viride), and GAM33347.1 (T. celluloliticus). Black color shows the conserved residues in all cases. Dark grey shows the amino acids with 1 or 2 variations. Light grey indicates the residues with 3 or more variations between the sequences

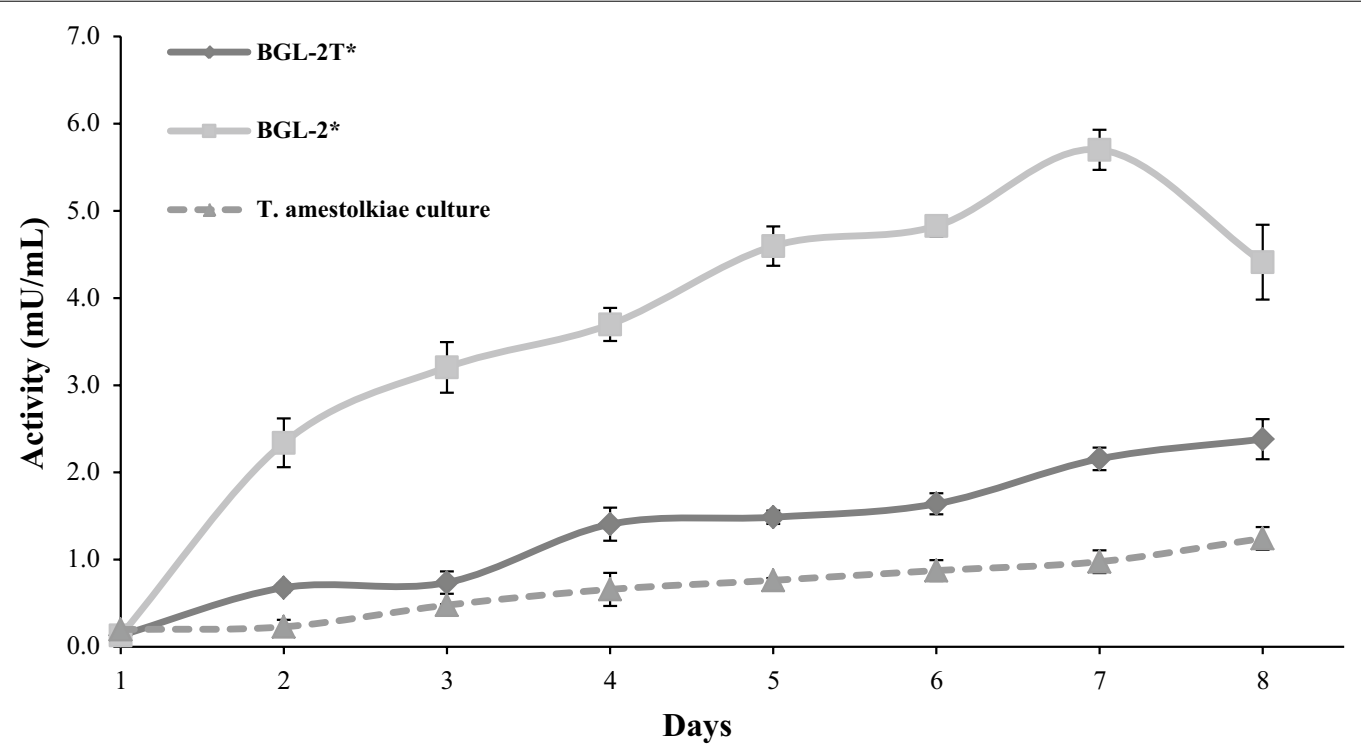

Fig. $4 \beta$-glucosidase activity secreted by T. amestolkiae in the presence of Avicel, and BGL-2* and BGL-2T* production in P.pastoris

glycosylated than the proteins with this domain. This could be explained in terms of protein composition, since BGL-2T* also lacks the linker region, where 39 possible glycosylation sites have been identified (Additional file 1: Figure S3). Linkers usually are strongly glycosylated, preventing proteolysis of this region $[21,22]$. 
Isoelectrofocusing indicated that the isoelectric point of purified $\beta$-glucosidases were 5.6, 7.4 and 5.2 for BGL-2, BGL2* and BGL-2T*, respectively. The major difference was found between BGL-2 and its recombinant form. The theoretical IEF value predicted from the BGL-2T* sequence was 4.89 , similar to the one obtained experimentally. However, for BGL-2* the theoretical value was 5.06. These differences between theoretical and experimental isoelectric points of the complete forms of the native and the recombinant enzyme, could be attributed to their different glycosylation patterns, that can affect the isoelectric point of a given protein [23].

Temperature and $\mathrm{pH}$ are crucial factors for the enzymatic hydrolysis of lignocellulosic biomass degradation. All BGL-2 isoforms studied were stable up to $40{ }^{\circ} \mathrm{C}$ after $72 \mathrm{~h}$. Remarkably, the lack of CBD increased the temperature stability of $\mathrm{BGL}-2 \mathrm{~T}^{*}$ to $50{ }^{\circ} \mathrm{C}$ after 3 days (Fig. 5a). BGL-2T* also was more stable in the most acidic and basic pH assayed (Fig. 5b). Optimal activity of BGL-2T* was obtained between $\mathrm{pH} 3-4$ and $70{ }^{\circ} \mathrm{C}$, while both, BGL-2 and BGL-2* showed their highest activity at a similar $\mathrm{pH}$ but at $60{ }^{\circ} \mathrm{C}$. These results suggest that all BGL-2 forms studied could be useful for biotechnological applications such as $2 \mathrm{G}$ ethanol production from lignocellulosic wastes, especially those acid-pretreated [24]. Comparing with the data obtained for other native $\beta$-glucosidases, all BGL- 2 forms had superior optimal temperatures [25] and were stable at broader $\mathrm{pH}$ ranges $[26,27]$. The recombinant $\beta$-glucosidases from Thermoascus aurantiacus [28], Aspergillus fumigatus [29], Myceliophthora thermophila [30], Neosartorya fischeri [31], Penicillium funiculosum [32] and Neurospora crassa [33], expressed in P. pastoris, had optimum temperatures similar to BGL-2*, between 60 and $70{ }^{\circ} \mathrm{C}$, with the exception of $N$. crassa, whose optimal temperature is $80{ }^{\circ} \mathrm{C}$. The optimal $\mathrm{pH}$ for these proteins was between 5 and 6 , whereas the optimum $\mathrm{pH}$ of the recombinant BGL-2 forms is more acidic.

The circular dichroism analysis of native and recombinant proteins revealed that all BGL-2 forms have a typical spectrum of $\alpha+\beta$ folded structures. The native and recombinant full-length proteins had very similar
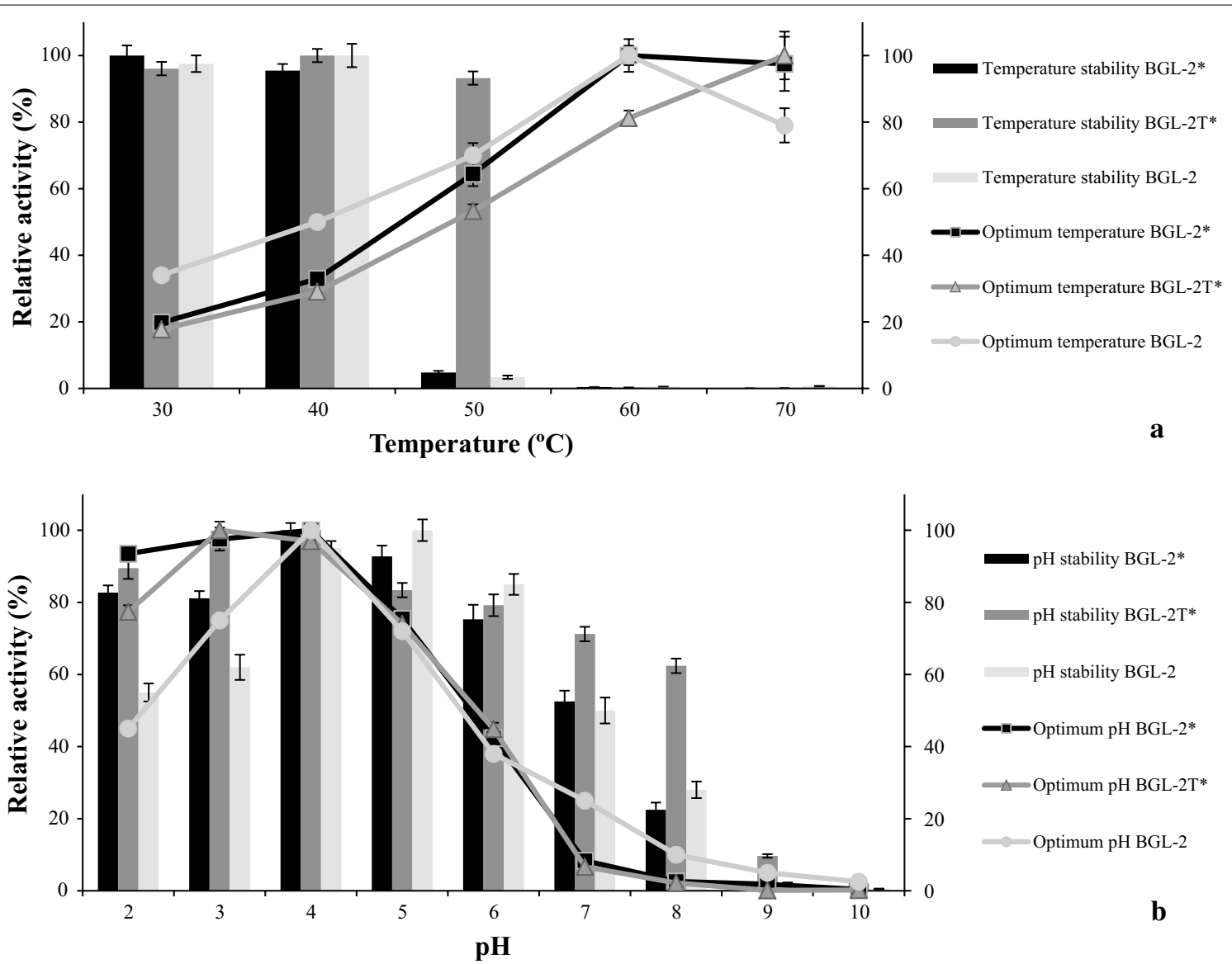

Fig. 5 Effect of temperature $\mathbf{a}$ and $\mathrm{pH} \mathbf{b}$ on BGL-2 enzyme activity. Lines indicate the optimum temperature or pH for enzyme activity; bars show its 72 h-stability in a range of temperatures from $30-70{ }^{\circ} \mathrm{C}$ or $\mathrm{pH}$ from 2 to 10 
spectra, confirming their common secondary structure. However, the spectrum of BGL-2T* lacked the minimum at $208 \mathrm{~nm}$ typical of proteins with CBD (Additional file 1: Figure S4). This study evidenced that the two forms of the protein do not have the same secondary structure, suggesting that BGL-2T* could have a slightly different folding. This may be one of the reasons for its increased stability to temperature and $\mathrm{pH}$. A recent report has shown the negative effect of excessive $O$-glycosylation on the $\mathrm{pH}$ stability of a recombinant $\beta$-glucosidase from Talaromyces leycettanus [34], which is in good agreement with the lower glycosylation degree and higher stability determined for BGL-2T* against those of the full-length proteins. However, the improved stability of BGL-2T* could be also explained in terms of protein composition: an endo- $\beta-1,4$-glucanase from Bacillus subtilis JA18 showed increased thermal stability and catalytic efficiency after CBD depletion [35]. These authors postulated that the increased stability could be related to an enhanced refolding after thermal stress in the absence of CBD. In this sense, the deletion of CBD and its linker could result in a more compact protein, with a larger fractional polar surface, increasing hydrogen bonding density to water [36].

\section{Cellulose binding assay}

To determine whether the CBD had the ability to bind cellulose, Avicel adsorption tests were performed with native and recombinant BGL-2, with and without CBD.

The results showed that native BGL-2 and BGL-2* quickly bind to Avicel, decreasing $\beta$-glucosidase activity in the supernatants, while no activity changes were observed in the supernatants of the assays with the truncated protein (Fig. 6). In addition, the interaction between Avicel and the proteins' CBD was strong and stable after $24 \mathrm{~h}$, which suggests that this domain is functional, and could play an important role in binding to natural cellulosic substrates. Finally we have examined the CBD binding ability to other polysaccharides like xylan and chitin. The results showed that the CBD of BGL-2 binds specifically to cellulose (Additional file 1 : Figure S5).

\section{Substrate specificity of the native and recombinant BGL-2 forms}

The three forms of BGL-2 hydrolyzed $p$ NPG, $o$ NPG and cellooligosaccharides from cellobiose to cellohexaose with different efficiency. As a general rule, the recombinant BGL-2 enzymes were more active and showed

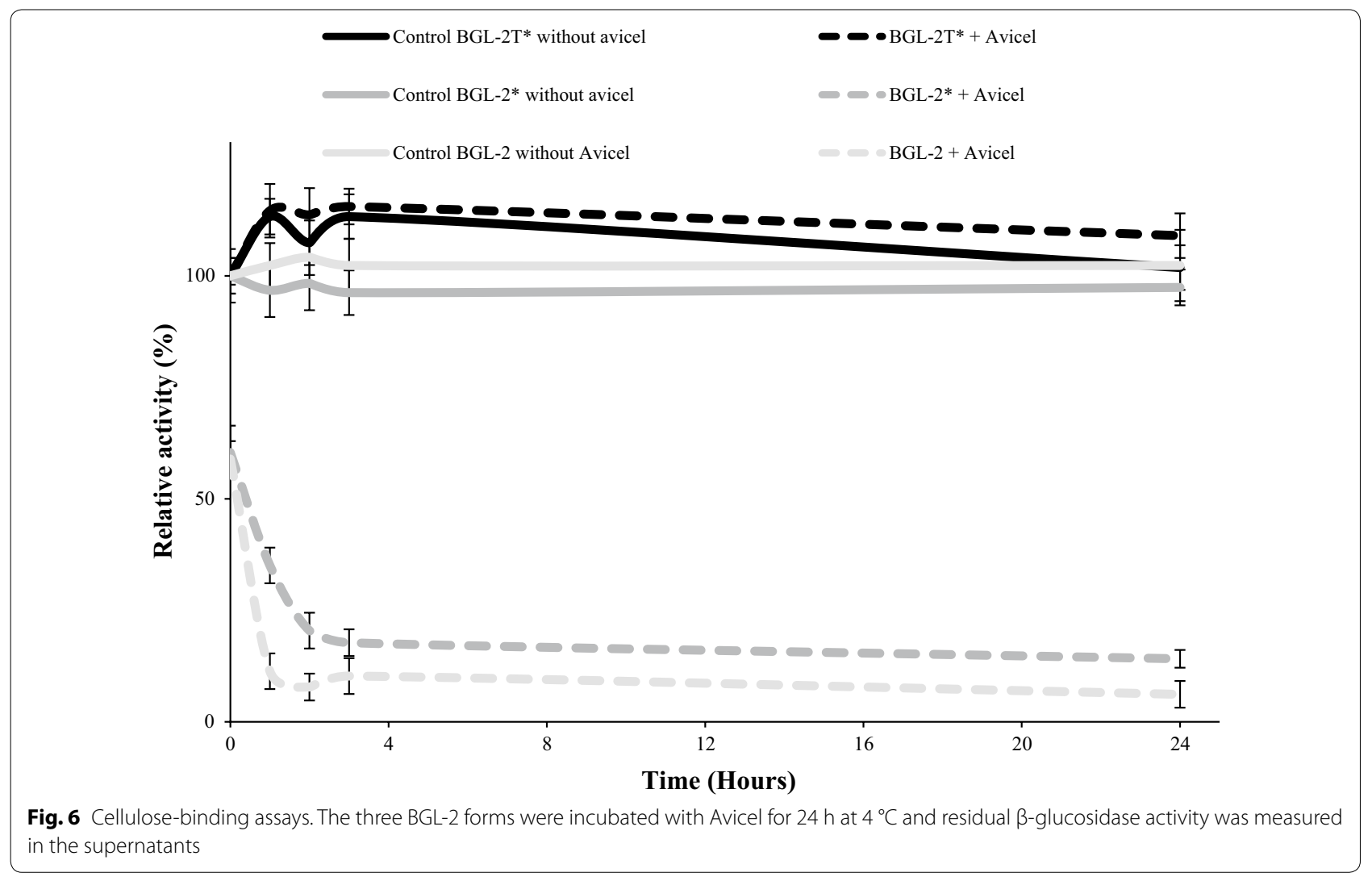


higher affinity towards all substrates tested. More specifically, BGL-2T* presented a superior catalytic efficiency towards all substrates but cellopentaose and cellohexaose (Table 2). In detail, it can be seen that the two recombinant proteins showed a better affinity for the longer cellooligosaccharides. The different catalytic efficiency of BGL-2* and BGL-2T* on cellooligosaccharides of different lengths could be related to the presence or absence of the CBD, since the role of CBMs in binding to cellotetraose or cellohexaose has already been demonstrated $[37,38]$. The higher catalytic efficiency of BGL-2T* on the shorter substrates could also be explained considering that the CBD could interfere with the access of small oligosaccharides to the catalytic site. On the other hand, the importance of the CBD to bind the enzyme to longer substrates, like cellopentaose and cellohexaose, might favor their hydrolysis rate, being responsible for the improved catalytic efficiency of these molecules by BGL$2^{*}$. The lower effect of the native BGL-2 on all the cellooligosaccharides assayed could be due to some negative effect on the integrity of the purified enzyme across its multistep purification process.

The kinetic parameters determined for all BGL-2 isoforms, and especially the recombinant enzymes, show that these enzymes are among the most efficient BGLs discovered up to now (Additional file 1: Table S1). However, very few studies describe high BGL activities on natural substrates as cellobiose or cellooligosaccharides, despite these are their typical substrates in saccharification processes [39]. All the BGL-2 isoforms analyzed hydrolyzed cellooligosaccharides $\mathrm{C} 2-\mathrm{C} 6$ more efficiently than all BGL studied so far (Table 3 ). These results put these enzymes in the forefront of the known $\beta$-glucosidases for the saccharification of these natural substrates, which is highly relevant from a biotechnological perspective.

A set of aryl glycosides and disaccharides were also assayed to test the enzymes' specificity. Residual activity levels were detected towards 4-nitrophenyl $\beta$-Dxylopyranoside and 4-nitrophenyl $\alpha$-D-glucopyranoside, and no activity was observed against 4-nitrophenyl $\beta$-Dgalactopyranoside, 4-nitrophenyl $\alpha$-D-galactopyranoside, 4-nitrophenyl $\alpha$-L-rhamnopyranoside, 4-nitrophenyl $\beta$-D-fucopyranoside, maltose, lactose or sucrose. Remarkably, the three enzymes were quite active towards laminaribiose and gentiobiose (data not shown).

In addition, all BGL-2 isoforms were capable of releasing reducing sugars from Avicel, carboxymethyl cellulose (CMC), and beechwood xylan (Table 4). This is quite unusual since polysaccharides are typically not degraded by these enzymes. It was noticeable that, unlike for small carbohydrates, the native enzyme and the recombinant BGL-2 had similar catalytic activity. The full-length BGL-2 showed slightly more specific activity against these polymers than the truncated enzyme. Hence, although the CBD is not strictly needed for BGL-2 to hydrolyze small soluble substrates, its presence increases polysaccharide conversion, probably by improving the enzyme binding. The activity over Avicel of a fungal $\beta$-glucosidase from $A$. fumigatus, expressed in P. pastoris, was significantly lower $(1.7 \mathrm{U} / \mathrm{mg})$ [29] than that detected for the BGL-2s from T. amestolkiae. On the contrary, a $\beta$-glucosidase from $P$. purpurogenum [40] showed higher specific activity, but it was inactive against other polysaccharides like xylan or CMC. In general, most investigations report that BGLs have no activity on polysaccharides. The ability of BGL-2 to hydrolyze these substrates shows its versatility to be used in industrial applications.

\section{Brewers spent grain saccharification}

The enzymatic conversion of cellulose to glucose is a crucial step in the production of bioethanol from lignocellulosic biomass. Since commercial cellulolytic cocktails based on enzymes from T. reesei, like celluclast, are usually deficient in $\beta$-glucosidase activity, they are

Table 2 Kinetic parameters of all BGL-2 isoforms against different substrates

\begin{tabular}{|c|c|c|c|c|c|c|c|c|c|}
\hline \multirow[t]{2}{*}{ Substrate } & \multicolumn{3}{|l|}{$K_{\mathrm{m}}(\mathrm{mM})$} & \multicolumn{3}{|c|}{$k_{\text {cat }}\left(s^{-1}\right)$} & \multicolumn{3}{|c|}{$\mathrm{k}_{\mathrm{cat}} / K_{\mathrm{m}}\left(\mathrm{mM}^{-1} \mathrm{~s}^{-1}\right)$} \\
\hline & BGL-2 & BGL-2* & BGL-2T* & BGL-2 & BGL-2* & BGL-2T* & BGL-2 & BGL-2* & BGL-2T* \\
\hline$p N P G$ & $0.41 \pm 0.02$ & $0.19 \pm 0.01$ & $0.34 \pm 0.02$ & 485 & 444 & 874 & 1167 & 2243 & 2563 \\
\hline oNPG & $0.86 \pm 0.04$ & $1.48 \pm 0.02$ & $0.67 \pm 0.04$ & 174 & 59 & 217 & 201 & 39 & 323 \\
\hline Cellobiose & $1.21 \pm 0.04$ & $1.11 \pm 0.02$ & $0.91 \pm 0.05$ & 303 & 630 & 569 & 249 & 567 & 619 \\
\hline Cellotriose & $1.37 \pm 0.05$ & $1.87 \pm 0.13$ & $1.42 \pm 0.06$ & 272 & 617 & 716 & 198 & 329 & 502 \\
\hline Cellotetraose & $1.68 \pm 0.04$ & $0.92 \pm 0.01$ & $0.49 \pm 0.03$ & 313 & 580 & 402 & 185 & 629 & 813 \\
\hline Cellopentaose & $1.28 \pm 0.02$ & $0.71 \pm 0.03$ & $0.68 \pm 0.01$ & 309 & 671 & 482 & 239 & 936 & 701 \\
\hline Cellohexaose & $1.01 \pm 0.04$ & $0.51 \pm 0.01$ & $0.49 \pm 0.03$ & 313 & 405 & 359 & 307 & 794 & 720 \\
\hline
\end{tabular}


Table 3 Comparison of cata lytic efficiencies against cellooligosaccharides ( $C 2-\mathrm{C} 6)$ of fungal $\beta$-glucosidases

\begin{tabular}{|c|c|c|c|c|c|c|c|c|c|c|}
\hline \multirow[t]{2}{*}{ Organism and reference } & \multirow[t]{2}{*}{ Enzyme } & \multirow{2}{*}{$\begin{array}{l}\text { Cellobiose } \\
K_{\text {cat }} / K_{m}\end{array}$} & \multicolumn{2}{|c|}{ Cellotriose } & \multicolumn{2}{|c|}{ Cellotetraose } & \multicolumn{2}{|c|}{ Cellopentaose } & \multicolumn{2}{|c|}{ Cellohexaose } \\
\hline & & & $K_{\mathrm{m}}$ & $V_{\max }$ & $K_{\mathrm{m}}$ & $V_{\max }$ & $K_{\mathrm{m}}$ & $V_{\max }$ & $K_{\mathrm{m}}$ & $V_{\max }$ \\
\hline \multicolumn{11}{|l|}{ Native BGLs } \\
\hline \multirow[t]{3}{*}{ Trichoderma reesei [50] } & Cel3A & 37.3 & 0.2 & 38.0 & & 41.0 & & & & \\
\hline & Cel3B & 21.6 & 0.3 & 36.0 & & 36.0 & & & & \\
\hline & Cel1A & 70.6 & 1.1 & 18.0 & & 2.6 & & & & \\
\hline Metagenome from compost [51] & $\mathrm{Td} 2 \mathrm{f} 2$ & 1.6 & 3.1 & 10.1 & 1.53 & 7.8 & 8.4 & 7.9 & & \\
\hline T. thermosaccharolyticum [52] & & 13.3 & & & & & & & & \\
\hline Penicillium purpurogenum [40] & & & & 111.0 & & 96.0 & & 68.4 & & \\
\hline \multicolumn{11}{|l|}{ BGLs expressed in P. pastoris } \\
\hline Aspergillus fumigatus [29] & rBgl3 & 52.1 & & & & & & & & \\
\hline Penicillium funiculosum [32] & $\mathrm{rBg} / 4$ & 3610.4 & & 59.4 & & 39.3 & & 32.7 & & 23.70 \\
\hline Neurospora crassa [33] & BGL2 & & & 12.3 & & 9.4 & & & & \\
\hline Myceliophthora thermophila [30] & MtBgl3a & 17.4 & & & & & & & & \\
\hline \multicolumn{11}{|l|}{ BGLs of this work } \\
\hline \multirow[t]{3}{*}{ T. amestolkiae } & BGL-2 & 249.1 & 1.37 & 167.8 & 1.69 & 193.1 & 1.2 & 190.7 & 1.0 & 193.2 \\
\hline & $B G L-2^{*}$ & 567.1 & 1.88 & 363.2 & 0.92 & 341.5 & 0.7 & 394.8 & 0.5 & 238.7 \\
\hline & BGL-2T & 619.1 & 1.43 & 532.2 & 0.50 & 298.9 & 0.6 & 358.1 & 0.5 & 266.9 \\
\hline
\end{tabular}

Table 4 Specific activity of BGL-2, BGL-2* and BGL-2T* against different polysaccharides

\begin{tabular}{lccccc}
\hline Substrate & \multicolumn{2}{l}{ Specific activity $\mathbf{( U / \mathbf { m g } )}$} & & & \\
\cline { 2 - 5 } & \multicolumn{1}{c}{ BGL-2 } & BGL-2* & BGL-2T & Celluclast 1.5 L $^{*}$ & Inactivated enzyme $^{\mathbf{a}}$ \\
\hline Avicel & $11.2 \pm 0.5$ & $15.8 \pm 0.4$ & $6.5 \pm 0.3$ & $4.4 \pm 0.2$ & $0.51 \pm 0.1$ \\
CMC & $9.1 \pm 0.2$ & $10.0 \pm 0.4$ & $5.4 \pm 0.4$ & $11.3 \pm 0.4$ & $0.88 \pm 0.12$ \\
Xylan & $21.6 \pm 0.2$ & $18.3 \pm 0.3$ & $14.2 \pm 0.2$ & $3.5 \pm 0.3$ & $0.74 \pm 0.12$ \\
\hline
\end{tabular}

a Boiled $20 \mathrm{~min}$

supplemented with this enzymatic activity for lignocellulosic biomass treatment. $\beta$-glucosidases from Penicillium sp. or Talaromyces sp. have successfully been applied for saccharification of cellulosic materials, being more efficient than Trichoderma sp. enzyme preparations, since they have higher $\beta$-glucosidase levels [41]. For saccharification of brewers spent grain, the synergistic effect of Celluclast $1.5 \mathrm{~L}$ and a $\beta$-glucosidase-rich supplement (the native or recombinant isoforms of T. amestolkiae BGL-2 or the commercial preparation NS-50010) were evaluated.

The results shown in Fig. 7 indicate that supplementation with any of the BGL-2 forms enhanced the saccharification of brewers spent grain, than using only celluclast (8\% with BGL-2, 32\% with BGL-2* and $24 \%$ for BGL-2T). The minor effect of the native $T$. amestolkiae protein could be related to their kinetic constants, slightly worse than those determined for the recombinant proteins against the substrates assayed. The differences found when Celluclast was supplemented with BGL-2T*, could indicate that the CBD could have a relevant role in binding cellulose in natural substrates increasing its degradation efficiency. Interestingly, the supplementation with BGL-2* showed a similar yield than with NS-50010. This is remarkable since BGL-2* is a purified protein, whereas NS-50010 is an enzyme cocktail, containing other cellulolytic and hemicellulolytic activities which could promote the yield of the saccharification process. Hence, this results suggest that both recombinant T. amestolkiae $\beta$-glucosidases, especially BGL-2*, could be suitable proteins in the valorization process of lignocellulosic biomass.

\section{Conclusions}

$\beta$-glucosidases are very versatile enzymes that play an essential role in the enzymatic hydrolysis of plant biomass for the production of $2 \mathrm{G}$ biofuels. In the present work, BGL-2 from $T$. amestolkiae was discovered, purified and characterized, standing out for being the first 1,4- $\beta$-glucosidase with a functional cellulose 


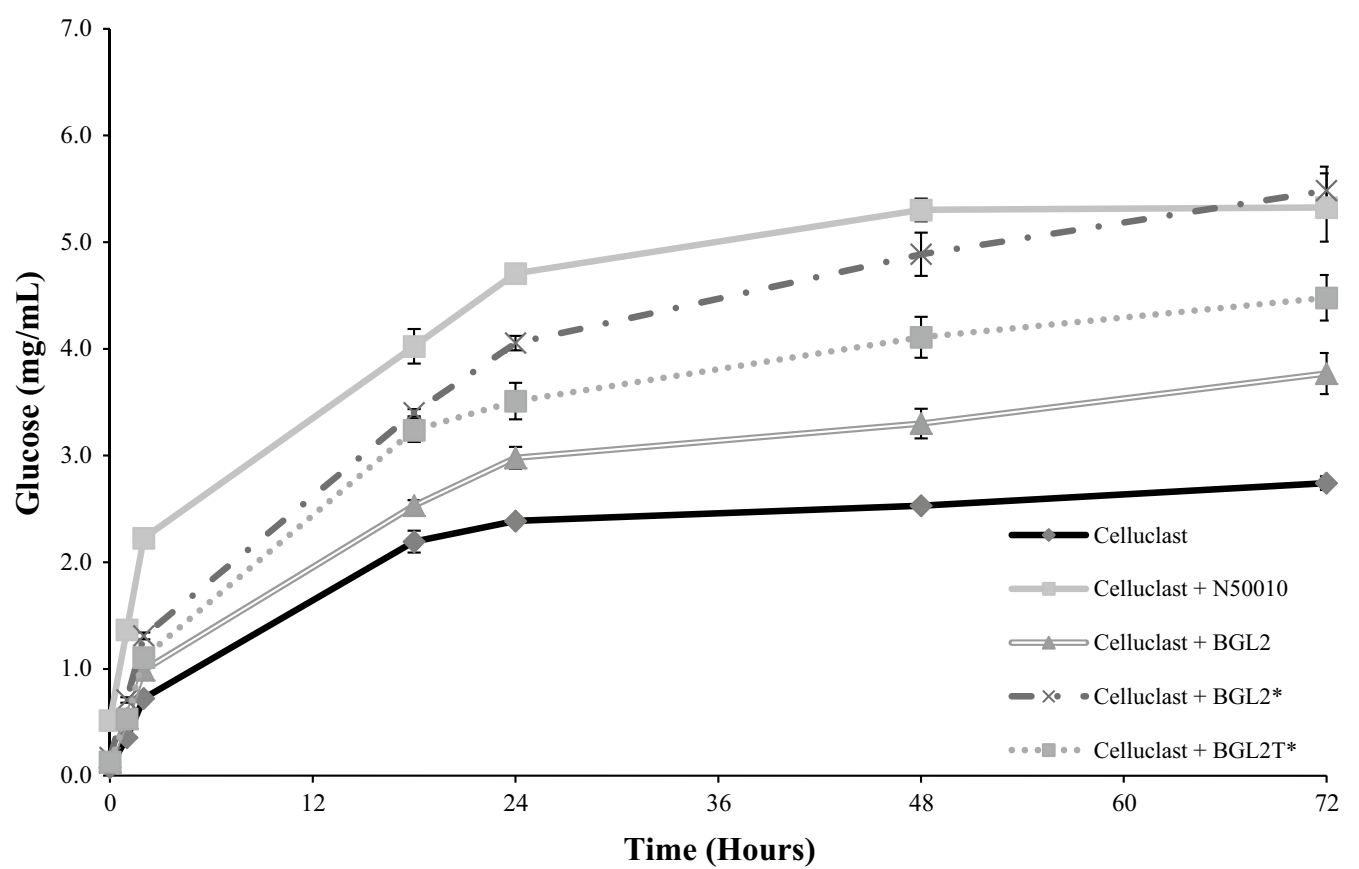

Fig. 7 Glucose yield from saccharification of brewers spent grain. Addition of one of the three BGL-2 enzymes or NS-50010 to Celluclast $1.5 \mathrm{~L}$ improved substrate degradation

binding domain, similar to others found in $\mathrm{CBHs}$ and EGs. Besides, an isoform without CBD was also isolated and characterized. The work has revealed the high potential of the native BGL-2 and its recombinant forms, with and without CBD, to be applied for the saccharification of plant biomass. The complete characterization of the cellulolytic system of this fungus is currently being carried out, with special interest in the purification of other $\beta$-glucosidases produced by this strain, to evaluate their properties and features to be used in different biotechnological applications.

\section{Methods}

\section{Microorganism and culture conditions}

The fungus used in this work, isolated from cereal samples by the group of Dr. Covadonga Vazquez (Department of Microbiology, Faculty of Biology, Complutense University of Madrid), was identified and included in the Collection of the Institute Jaime Ferrán of Microbiology (IJFM) with the number A795. The fungus was grown in potato dextrose agar (PDA) for 5 days at $28^{\circ} \mathrm{C}$. Spore suspensions were obtained by placing $1 \mathrm{~cm}^{2}$ agar slants in $5 \mathrm{~mL}$ of a $1 \% \mathrm{NaCl}$ solution, and $0.1 \%$ of Tween 80 . The mixture was shaken and $200 \mu$ l were used to inoculate $250 \mathrm{~mL}$ flasks with $50 \mathrm{~mL}$ of CSS medium $(40 \mathrm{~g} / \mathrm{L}$ glucose, $0.4 \mathrm{~g} / \mathrm{L} \mathrm{FeSO}_{4} \cdot 7 \mathrm{H}_{2} \mathrm{O}, 9 \mathrm{~g} / \mathrm{L}\left(\mathrm{NH}_{4}\right)_{2} \mathrm{SO}_{4}, 4 \mathrm{~g} / \mathrm{L}$ $\mathrm{K}_{2} \mathrm{HPO}_{4}, 26.3 \mathrm{~g} / \mathrm{L}$ corn steep solid, $7 \mathrm{~g} / \mathrm{L} \mathrm{CaCO}_{3}$, and
$2.8 \mathrm{~mL} / \mathrm{L}$ soybean oil). The culture was incubated at $28^{\circ} \mathrm{C}$ and 250 rpm for 5 days.

To grow T. amestolkiae for enzyme production, $2 \mathrm{~mL}$ from a CSS culture were inoculated in Mandels medium [42], composed by: $2.0 \mathrm{~g} / \mathrm{L} \mathrm{KH}_{2} \mathrm{PO}_{4}, 1.3 \mathrm{~g} / \mathrm{L}\left(\mathrm{NH}_{4}\right)_{2} \mathrm{SO}_{4}$, $0.3 \mathrm{~g} / \mathrm{L}$ urea, $0.3 \mathrm{~g} / \mathrm{L} \mathrm{MgSO}_{4} \cdot 7 \mathrm{H}_{2} \mathrm{O}, 0.3 \mathrm{~g} / \mathrm{L} \mathrm{CaCl}_{2}$, $5 \mathrm{mg} / \mathrm{L} \mathrm{FeSO}_{4} \cdot 7 \mathrm{H}_{2} \mathrm{O}, 1.6 \mathrm{mg} / \mathrm{L} \mathrm{MnSO}_{4} \cdot \mathrm{H}_{2} \mathrm{O}, 1.4 \mathrm{mg} / \mathrm{L}$ $\mathrm{ZnSO}_{4} \cdot 7 \mathrm{H}_{2} \mathrm{O}$, and $1 \mathrm{~g} / \mathrm{L}$ Bacto peptone. The $\mathrm{pH}$ was adjusted to 4.5. This medium was supplemented with $1 \%$ Avicel (microcrystalline cellulose) as carbon source and inducer of cellulolytic activities. The inoculated flasks were incubated at $28{ }^{\circ} \mathrm{C}$ and $250 \mathrm{rpm}$ for 8 days, taking daily culture samples for analytical determinations.

Escherichia coli DH5 $\alpha$ (Invitrogen) was used for plasmid propagation. It was grown in LB medium $(10 \mathrm{~g} / \mathrm{L}$ tryptone, $5 \mathrm{~g} / \mathrm{L}$ yeast extract, $10 \mathrm{~g} / \mathrm{L} \mathrm{NaCl}$, and $15 \mathrm{~g} / \mathrm{L}$ agar), at $37{ }^{\circ} \mathrm{C}$, overnight. For the growth and selection of ampicillin resistant transformants, this antibiotic was included in the LB medium, as its sodium salt, in a final concentration of $100 \mathrm{mg} / \mathrm{L}$, and bacteria were grown overnight at $37^{\circ} \mathrm{C}$.

The heterologous expression of $\beta$-glucosidases were performed using $P$. pastoris KM71 strain (Invitrogen) as a host, which was preserved in YPD medium plates $(10 \mathrm{~g} / \mathrm{L}$ yeast extract, $20 \mathrm{~g} / \mathrm{L}$ peptone, $20 \mathrm{~g} / \mathrm{L}$ glucose and $10 \mathrm{~g} / \mathrm{L}$ of agar). The transformants were screened in a selective medium, YNB-His (20 g/L glucose, $6.7 \mathrm{~g} / \mathrm{L}$ YNB, $1.92 \mathrm{~g} / \mathrm{L}$ 
Yeast synthetic drop-out medium supplements without histidine (Sigma-Aldrich), and $10 \mathrm{~g} / \mathrm{L}$ agar), and cultured $72 \mathrm{~h}$ at $28{ }^{\circ} \mathrm{C}$. Finally, for recombinant protein production, YEPS medium was used $(20 \mathrm{~g} / \mathrm{L}$ peptone, $10 \mathrm{~g} / \mathrm{L}$ yeast extract, $10 \mathrm{~g} / \mathrm{L}$ sorbitol, and $100 \mathrm{mM}$ potassium phosphate buffer, $\mathrm{pH}$ 6), with daily addition of $6.5 \mathrm{~mL} / \mathrm{L}$ of methanol as inducer. Cultures were incubated for 7 days, at $28{ }^{\circ} \mathrm{C}$ and $250 \mathrm{rpm}$, taking samples daily to measure protein production. All experiments were performed by triplicates.

\section{Purification and characterization of native and recombinant proteins}

All protein purifications were performed using an AKTA Purifier HPLC system (GE Healthcare Life Sciences). The native BGL-2 protein from T. amestolkiae was purified from protein extracts obtained after fungus growth in Mandels medium with 1\% Avicel after 8 days of incubation, when maximal activity was detected. Culture supernatants were filtered, concentrated, and dialyzed though a $10 \mathrm{kDa}$ cutoff membrane against $10 \mathrm{mM}$ sodium phosphate $\mathrm{pH} 6$, which is the buffer used across all the chromatographic steps required to purify the protein. The concentrate crude was first applied onto a Capto Adhere HiTrap cartridge (GE Healthcare Life Sciences) equilibrated with buffer using a $1 \mathrm{~mL} / \mathrm{min}$ flow. Peak 1 eluted during the $\mathrm{NaCl}$ gradient (from 0 to $0.5 \mathrm{M}$ ), while peak 2 eluted once the gradient had finished, during reequilibration of the cartridge in the starting buffer. Fractions with high $\beta$-glucosidase activity were pooled, concentrated and tested for purity. The second purification step involved anion-exchange chromatography in a high resolution Mono Q column (GE Healthcare Life Sciences) equilibrated with $10 \mathrm{mM}$ sodium phosphate buffer, $\mathrm{pH}$ 6 , at a flow rate of $0.8 \mathrm{~mL} / \mathrm{min}$. The retained proteins were eluted with a linear $\mathrm{NaCl}$ gradient $(0-0.25 \mathrm{M}$ over $50 \mathrm{~min}$ ). Then the column was washed with $1 \mathrm{M} \mathrm{NaCl}$ for $7 \mathrm{~min}$ and equilibrated in the initial conditions. As above, the fractions with BGL activity were pooled, concentrated, and tested for purity. A third step of size exclusion chromatography on Superdex 75 HR 10/30 (GE Healthcare Life Sciences) was required to achieve BGL-2 purification. The column was equilibrated and the proteins eluted in the same buffer with $100 \mathrm{mM} \mathrm{NaCl}$ to avoid unspecific interactions, at a $0.3 \mathrm{~mL} / \mathrm{min}$ flow.

In the case of the recombinant enzymes, the purification was achieved in a single chromatographic step. $P$. pastoris cultures producing the maximal BGL activity ( 8 days old) were centrifuged and the supernatant was then concentrated, dialyzed and applied to a Capto Adhere HiTrap cartridge (GE Healthcare Life Sciences) in the same conditions as native protein. Once the $\mathrm{NaCl}$ gradient (from 0 to $0.5 \mathrm{M}$ ) was finished and the cartridge reequilibrated, a peak with pure BGL-2 isoforms was obtained.

In all chromatographic steps, protein concentration $\left(\mathrm{A}_{280 \mathrm{~nm}}\right)$ and $\beta$-glucosidase activity, using $p$-nitrophenyl$\beta$-D-glucopyranoside ( $p$ NPG) as substrate, were measured. Protein homogeneity was checked after each purification step by $10 \%$ SDS-PAGE staining with Coomassie brilliant blue R-250. The approximate molecular mass of the proteins was calculated by this technique comparing the migration of the bands with those of the molecular weight markers provided by Bio-Rad. The accurate determination of the protein molecular mass was done by MALDI-TOF.

\section{Identification of $\mathrm{BGL}-2$ by peptide mass fingerprinting}

Purified proteins were loaded on a 10\% SDS-PAGE gel that, after the electrophoretic run, was stained with Sypro Ruby. Small pieces from the protein band were excised and digested with trypsin in accordance with the protocol reported by Shevchenko et al. [43]. MALDI-MS and MALDI-MS/MS data were obtained automatically in a mass spectrometer MALDI-TOF/TOF Autoflex III (Bruker Daltonics) equipped with a laser and a Smartbeam LIFT-MS/MS device. The data obtained were combined using the 3.0 BioTools (Bruker Daltonics) software, and mass values from trypsin, keratin, matrix or sodium adducts were removed. Data analysis was performed against the NCBInr database (National Center for Biotechnology Information non-redundant) with the 2.3 MASCOT search engine (Matrix Science). Relevant search parameters were set as follows: trypsin as enzyme, carbamidomethylation of cysteines as fixed modification, methionine oxidation as variable modification, 1 missed cleavage allowed, peptide tolerance of $50 \mathrm{ppm}$, and MS/ MS tolerance of $0.5 \mathrm{Da}$. Protein scores greater than 75 were considered significant.

\section{Nucleic acid isolation, PCR and RT-PCR methods}

Mycelium from cultures grown in Mandels medium was used for genomic DNA and RNA extraction after filtration of 8 days old cultures with $0.8 \mu \mathrm{m}$ nitrocellulose filters. DNA and RNA extraction were carried out using DNeasy Plant Mini Kit and RNeasy Plant Mini Kit (Qiagen) respectively, according to the manufacturer instructions. The extracted nucleic acids were quantified using a NanoDrop ND-100 (Thermo Scientific).

Isolated transcripts were converted to cDNA using the Superscript II Reverse Transcriptase RT-PCR kit (Invitrogen) using $50 \mu \mathrm{M}$ random hexamers. PCR amplifications were performed in a thermocycler Mastercycler pro $\mathrm{S}$ (Eppendorf) using genomic DNA as template. Reaction mixtures were subjected to an initial denaturation at $95{ }^{\circ} \mathrm{C}$ for $5 \mathrm{~min}$, followed by 36 cycles of amplification of 
$95{ }^{\circ} \mathrm{C}$ of denaturation for $45 \mathrm{~s}, 50{ }^{\circ} \mathrm{C}$ for $45 \mathrm{~s}$ of primer annealing step, and $72{ }^{\circ} \mathrm{C}$ for $3 \mathrm{~min}$ of elongation, followed by a final extension step at $72{ }^{\circ} \mathrm{C}$ for $10 \mathrm{~min}$. The amplified sequences were separated in a $0.8 \%(\mathrm{w} / \mathrm{v})$ agarose electrophoresis gel stained with GelRed, cut out, and purified using a QIAquick gel extraction kit (Qiagen). For amplifying $b g l 2$ gene from cDNA, two primers with restriction sites were used: $F w-B G L 2 S n a B I$ (5'TACGTACAGTCAGCTTCTTGGTCCGCAG3') and $R V$-NotIBGL2 (5'GCGGCCGCCTATTGTAGGCATTG AGAATACCACTGATTC3'). PCR reaction mixtures contained: $1 \times$ PCR Buffer; $1.5 \mathrm{mM} \mathrm{MgCl}$; $0.25 \mathrm{mM}$ dNTPs; $0.25 \mathrm{mM}$ forward and reverse primers; $100 \mathrm{ng}$ of DNA template; and $0.05 \mathrm{U} / \mathrm{mL}$ of Taq polymerase.

\section{Plasmid construction, E. coli propagation and heterologous expression}

For $b g l 2$ heterologous expression, the amplification product was digested with SnaBI and NotI restriction enzymes, and was ligated to pPIC9 vector, previously digested with the same enzymes, using T4 phage ligase (Promega). Plasmids which contain bgl2 wild type and bgl2 retaining the third intron were built and sequenced using the BigDye Terminator v3.1 cycle sequencing kit and the automated ABI Prism 3730 DNA sequencer, in Secugen (Madrid, Spain).

The plasmids obtained from E. coli positive clones were linearized with SalI, and transformed into KM71 $P$. pastoris strain by the lithium chloride transformation method, according to the Pichia expression kit (Invitrogen). The transformants were screened by histidine auxotrophy in YNB-His medium.

Selected clones on YNB-His plates were cultured on YPM medium $(10 \mathrm{~g} / \mathrm{L}$ yeast extract, $10 \mathrm{~g} / \mathrm{L}$ peptone, and $10 \mathrm{~g} / \mathrm{L}$ of agar; after autoclaving the medium, $15 \mathrm{~mL} / \mathrm{L}$ sterile methanol was added), to identify positive transformants. The yeasts were cultured $24 \mathrm{~h}$ at $28{ }^{\circ} \mathrm{C}$. The plates were covered with a solution of $50 \mathrm{mM}$ 4-methylumbelliferyl- $\beta$-D-glucopyranoside (MUG) in $100 \mathrm{mM}$ sodium acetate buffer and $0.8 \%$ agar. After solidifying, the plate was introduced in an oven at $50{ }^{\circ} \mathrm{C}$ for $20 \mathrm{~min}$, and positive clones were revealed in a transilluminator Bio Rad Gel Doc XR. Clones with $\beta$-glucosidase activity hydrolyze MUG, releasing methylumbelliferyl, which is fluorescent at UV wavelength [32].

\section{Physicochemical properties and homology modeling}

The accurate molecular mass and homogeneity of the pure enzyme were analyzed by matrix-assisted laser desorption ionization-time of flight mass spectrometry (MALDI-TOF) using an Autoflex III instrument (Bruker Daltonics).
To know if the $\beta$-glucosidases of T. amestolkiae were glycoproteins, the PAS (Periodic Acid-Schiff) staining method was used using the Schiff reagent (Sigma), following the manufacturer instructions. The glycoproteins exhibit visible red-purple bands after approximately $20 \mathrm{~min} . \mathrm{N}$ - and $\mathrm{O}$-deglycosylation assays of purified proteins were carried out using Endoglycosidase $H$ or $O$-glycosidase (Roche), according to the manufacturer instructions. Differences in molecular mass before and after deglycosylation were analyzed by SDS-PAGE electrophoresis, as described above. The possible glycosylation sites of BGL-2 were also analyzed with NetNGlyc 1.0 Server (http://www.cbs.dtu.dk/services/NetNGlyc/). Protein sequence was also submitted to the SignalP 4.1 server for identifying and locating the signal peptide, which was excluded from the mass prediction.

The isoelectric point of the native and recombinant proteins was determined by isoelectrofocusing on $5 \%$ polyacrylamide gels using $\mathrm{pH}$ 3-10 ampholytes (GE Healthcare), with $1 \mathrm{M} \mathrm{H}_{3} \mathrm{PO}_{4}$ and $1 \mathrm{M} \mathrm{NaOH}$ as anode and cathode buffers, respectively. The $\mathrm{pH}$ gradient was measured directly on the gel using a contact electrode (Crison). $\beta$-glucosidase activity was detected after incubation of the gels with $2 \mathrm{mM} p$-methylumbelliferyl- $\beta$ D-glucopyranoside (Sigma-Aldrich), with fluorescence visualized under UV light by use of the Gel Doc XR + system (Bio-Rad).

The effect of $\mathrm{pH}$ on the BGLs was assessed using $100 \mathrm{mM}$ Britton and Robinson buffer [44], which can be adjusted to a broad range of $\mathrm{pH}(2-10)$ Optimal $\mathrm{pH}$ of the pure BGLs was tested using $p$ NPG as substrate in the same buffer, and to study their stability to $\mathrm{pH}$, the samples were incubated from $\mathrm{pH} 2$ to 10 for $72 \mathrm{~h}$ at $4{ }^{\circ} \mathrm{C}$. The effect of temperature on enzymes activity was analyzed subjecting solutions of the pure enzymes in $100 \mathrm{mM}$ sodium acetate buffer, $\mathrm{pH} 4$ to temperatures between 30 and $80^{\circ} \mathrm{C}$ for $10 \mathrm{~min}$ to determine their optimal temperature, and at 30 and $70{ }^{\circ} \mathrm{C}$ for $72 \mathrm{~h}$ to evaluate their thermostability.

Three dimensional models were generated by homology using the SWISS-MODEL server [45], based on sequence similarity. The QMEAN index is used to select the best models, which are ideal when the number is close to zero. The PyMol v0.99 [46] program was used to visualize and analyze the structures.

\section{Circular dichroism spectroscopy}

Circular dichroism analysis of the native and recombinant BGL-2 forms were performed to compare their secondary structure. Measurements were carried out using a JASCO J-720 spectropolarimeter. Far-UV spectra (190$260 \mathrm{~nm}$ ) were recorded in a $0.1 \mathrm{~cm}$ path length quartz cell 
at a protein concentration of $0.1 \mathrm{mg} / \mathrm{mL}$ in $10 \mathrm{mM}$ phosphate buffer. The spectra from five scans were averaged and corrected for the baseline contribution of the buffer. The observed ellipticities were converted into mean residue ellipticities $(\theta)$ based on a mean molecular mass (per amino acid residue) of $110 \mathrm{Da}$.

\section{Protein quantification, enzyme assays and substrate specificity}

In this study, all enzyme assays were performed in the presence of BSA $(0.1 \%)$, a protein that does not affect the catalytic activity of the BGL but prevents missing activity when working at low enzyme concentrations [47].

Total protein was estimated by the bicinchoninic acid assay (BCA) method, using bovine serum albumin as standard. BGL activity was usually determined at $60{ }^{\circ} \mathrm{C}$ versus $p$-nitrophenyl- $\beta$-D-glucopyranoside ( $p$ NPG) in $50 \mathrm{mM}$ acetate buffer $\mathrm{pH} 4$, and $0.2 \%$ of BSA (standard assay). The reaction was stopped with $500 \mu \mathrm{L}$ of sodium carbonate $(2 \% \mathrm{w} / \mathrm{v})$, and the release of $p$-nitrophenol $(p \mathrm{NP})$ was measured in a spectrophotometer at $410 \mathrm{~nm}$. One unit of BGL activity was defined as the amount of enzyme capable of hydrolyzing $1 \mu \mathrm{mol}$ of $p$ NPG to glucose and $p$ NP per minute. The same conditions were used to measure hydrolysis of $o$-nitrophenyl$\beta$-D-glucopyranoside (oNPG) and other nitrophenol derivatives.

BGLs were also incubated with different cellooligosaccharides. Its activity was determined against cellobiose, cellotriose, cellotetraose, cellopentaose, and cellohexaose, in 10 min-reactions carried out in sodium acetate $100 \mathrm{mM}, \mathrm{pH} 4$, mixing at $1200 \mathrm{rpm}$. The released glucose was measured using the Glucose-TR (Spinreact) commercial kit, according to the manufacturer's instructions.

The kinetic constants of the purified BGLs were determined by incubating the enzymes at their optimal $\mathrm{pH}$ and temperatures. The following substrates were analyzed over the range of concentrations stated in each particular case: $p$ NPG (from 10 to $5 \mathrm{mM}$ ), $o$ NPG (40$20 \mathrm{mM})$, cellobiose $(80-40 \mathrm{mM})$, cellotriose $(80-40 \mathrm{mM})$, cellotetraose $(80-40 \mathrm{mM})$, cellopentaose $(40-20 \mathrm{mM})$, and cellohexaose (20-10 mM). The values of $K_{\mathrm{m}}$ and $V_{\max }$ were determined from Lineweaver-Burk linear equation of the Michaelis-Menten model, using the program Sigmaplot.

The activity of BGL-2, BGL-2* and BGL-2T* was also determined against different polysaccharides, prepared in $50 \mathrm{mM}$ sodium acetate buffer $\mathrm{pH} 4: 1.25 \%(\mathrm{w} / \mathrm{v})$ Avicel (microcrystalline cellulose), 3\% (w/v) Carboxymethyl cellulose (CMC), and 3\% (w/v) beechwood xylan. The reaction mixture was incubated in a heating block at $1200 \mathrm{rpm}$ for $10 \mathrm{~min}$. After the incubation time, the reducing substances released was determined by the Somogyi-Nelson method [48], measuring $A_{540 \mathrm{~nm}}$.

A control without enzyme was included in all assays, to substrate the absorbance due to reactants. Also, a negative control with inactivated (boiled $20 \mathrm{~min}$ ) enzyme was included to discard unspecific interactions with substrates. Celluclast $1.5 \mathrm{~L}$ (Novozymes) was included as positive control in CMCase, Avicelase and xylanase assays.

\section{Cellulose binding assay}

To evaluate the ability of native BGL- 2 and its recombinant forms to bind microcrystalline cellulose and the participation of the CBD in this interaction, adsorption tests on Avicel were performed [49]. 20-30 ng of the purified enzymes were mixed with $500 \mu \mathrm{L}$ of $1 \%$ Avicel $(w / v)$ in $55 \mathrm{mM}$ sodium acetate buffer $\mathrm{pH}$ 4. The reaction was carried out at $1200 \mathrm{rpm}$ and $4{ }^{\circ} \mathrm{C}$ for $24 \mathrm{~h}$. Aliquots were taken at different times (10 min, 1, 2, 3 and $24 \mathrm{~h}$ ) after centrifuging the samples for $1 \mathrm{~min}$ at 14,000 rpm, before measuring residual BGL activity in the supernatants.

\section{Brewers spent grain saccharification}

The efficiency of the different BGL-2 forms as $\beta$-glucosidase supplements for the saccharification of lignocellulosic residues was tested following the release of glucose from brewers spent grain. Mixtures of Celluclast $1.5 \mathrm{~L}$ and either purified BGL-2 enzymes or NS-50010, a commercial cocktail with high $\beta$-glucosidase activity, were used as catalysts. Brewers spent grain $(100 \mathrm{mg})$ was treated with $2 \mathrm{~mL}$ of an enzymatic solution in $100 \mathrm{mM}$ sodium acetate buffer, $\mathrm{pH} 4$, containing a total of 2 BGL $\mathrm{U} / \mathrm{mL}: 1 \mathrm{U} / \mathrm{mL}$ from Celluclast $1.5 \mathrm{~L}$ and $1 \mathrm{U} / \mathrm{mL}$ from the BGL sources compared (NS-50010 or purified BGL-2 enzymes). Reactions were performed in a heat block at $50{ }^{\circ} \mathrm{C}$ and $1200 \mathrm{rpm}$ for $72 \mathrm{~h}$. Free glucose was measured at different reaction times using the Glucose-TR commercial kit (Spinreact).

\section{Additional file}

Additional file 1: Table S1. Comparison of the kinetic parameters reported or calculated for different fungal $\beta$-glucosidases using pNPG as model substrate. Figure $\mathbf{S 1}$. Sequence of $b g / 2$ from T. amestolkiae. Figure S2. MALDI-TOF mass spectra of $B G L-2 T^{*}$ and $B G L-2^{*}$. Figure $\mathbf{S 3}$. Protein sequence of BGL-2. Figure S4. Circular dichroism spectra (far UV spectrum) of purified BGL-2 isoforms. Figure S5. Cellulose-binding assays of BGL-2* against Xylan and Chitin, compared with Avicel.

\section{Abbreviations}

BGL: $\beta$-1,4 glucosidase; MALDI-TOF: matrix-assisted laser desorption/ionization-time of flight; GH: glycosyl hydrolase; CMC: carboxymethyl cellulose; HPLC: high performance liquid chromatography; $p N P$ : $p$-nitrophenol; CBD: cellulose binding domain. 


\section{Authors' contributions}

$J M, J G, M N$ and LdE contributed to design the research and participated in the experiments. JM, LdE and JG worked with native BGL-2. JM developed the work with recombinant enzymes. JB performed the homology modeling of the enzyme. JM drafted the manuscript. MJM and LdE co-coordinated the research and reviewed and edited the manuscript. All authors read and approved the final manuscript.

\section{Acknowledgements}

The authors thank the Proteomics and Genomics facility at CIB, Novozymes for providing the commercial cocktails, and Heineken for supplying brewers spent grain.

\section{Competing interests}

The authors declare that they have no competing interests.

\section{Availability of data and materials}

T amestolkiae whole genome shotgun project is deposited at DDBJ/ENA/ GenBank under the Accession Number MIKG00000000. BGL-2 sequence is deposited in GenBank under the Accession Number KM393203.

\section{Funding}

This work has been funded by Projects RTC-2014-1777-3 and BIO2015-68387-R from MINECO and S2013/MAE-2907 from Comunidad de Madrid. J.A. Méndez thanks its fellowship to Tatiana Pérez de Guzmán el Bueno Foundation. M. Nieto thanks its FPU fellowship to MINECO.

\section{Publisher's Note}

Springer Nature remains neutral with regard to jurisdictional claims in published maps and institutional affiliations.

Received: 14 July 2017 Accepted: 26 October 2017

Published online: 06 November 2017

\section{References}

1. Naik SN, Goud VV, Rout PK, Dalai AK. Production of first and second generation biofuels: a comprehensive review. Renew Sustain Energy Rev. 2010;14:578-97.

2. Amorim HV, Lopes ML, de Castro Oliveira JV, Buckeridge MS, Goldman $\mathrm{GH}$. Scientific challenges of bioethanol production in Brazil. Appl Microbiol Biotechnol. 2011;91:1267.

3. Lin Y, Tanaka S. Ethanol fermentation from biomass resources: current state and prospects. Appl Microbiol Biotechnol. 2006;69:627-42.

4. Alvira P, Tomás-Pejó E, Ballesteros M, Negro MJ. Pretreatment technologies for an efficient bioethanol production process based on enzymatic hydrolysis: a review. Biores Technol. 2010;101:4851-61.

5. Martínez ÁT, Ruiz-Dueñas FJ, Martínez MJ, del Río JC, Gutierrez A. Enzymatic delignification of plant cell wall: from nature to mill. Curr Opin Biotechnol. 2009;20:348-57.

6. Payne CM, Knott BC, Mayes HB, Hansson H, Himmel ME, Sandgren M, et al. Fungal cellulases. Chem Rev. 2015;115:1308-448.

7. Boraston AB, Bolam DN, Gilbert HJ, Davies GJ. Carbohydrate-binding modules: fine-tuning polysaccharide recognition. Biochem J. 2004;382:769.

8. Singhania RR, Sukumaran RK, Patel AK, Larroche C, Pandey A. Advancement and comparative profiles in the production technologies using solid-state and submerged fermentation for microbial cellulases. Enzyme Microbial Technol. 2010;46:541-9.

9. Maeda RN, Serpa VI, Rocha VAL, Mesquita RAA, Anna LMMS, de Castro AM, et al. Enzymatic hydrolysis of pretreated sugar cane bagasse using Penicillium funiculosum and Trichoderma harzianum cellulases. Process Biochem. 2011;46:1196-201.

10. Singhania RR, Saini JK, Saini R, Adsul M, Mathur A, Gupta R, et al. Bioethanol production from wheat straw via enzymatic route employing Penicillium janthinellum cellulases. Biores Technol. 2014;169:490-5.

11. de Eugenio LI, Méndez-Líter JA, Nieto-Domínguez M, Alonso L, Gil-Muñoz J, Barriuso J, et al. Differential $\beta$-glucosidase expression as a function of carbon source availability in Talaromyces amestolkiae: a genomic and proteomic approach. Biotechnol Biofuels. 2017;10:161.

12. Maruyama N, Katsube T, Wada Y, Oh MH, De la Rosa APB, Okuda E, et al. The roles of the $\mathrm{N}$-linked glycans and extension regions of soybean betaconglycinin in folding, assembly and structural features. Eur J Biochem. 1998:258:854-62.

13. Gilkes NR, Claeyssens M, Aebersold R, Henrissat B, Meinke A, Morrison HD, et al. Structural and functional-relationships in 2 Families of beta-1,4-glycanases. Eur J Biochem. 1991;202:367-77.

14. Srisodsuk M, Reinikainen T, Penttila M, Teeri TT. Role of the interdomain linker peptide of Trichoderma reesei cellobiohydrolase-l in its interaction with crystalline cellulose. J Biol Chem. 1993;268:20756-61.

15. Lymar ES, Li B, Renganathan V. Purification and characterization of $A$ cellulose-binding beta-glucosidase from cellulose-degrading cultures of Phanerochaete chrysosporium. Appl Environ Microbiol. 1995;61:2976-80.

16. Igarashi K, Tani T, Kawai R, Samejima M. Family 3 beta-glucosidase from cellulose-degrading culture of the white-rot fungus Phanerochaete chrysosporium is a glucan 1,3-beta-glucosidase. J Biosci Bioeng. 2003;95:572-6.

17. Karkehabadi S, Helmich KE, Kaper T, Hansson H, Mikkelsen NE, Gudmundsson $\mathrm{M}$, et al. Biochemical characterization and crystal structures of a fungal Family 3 beta-glucosidase, Cel3A from Hypocrea jecorina. J Biol Chem. 2014:289:31624-37.

18. Suzuki K, Ji Sumitani, Nam YW, Nishimaki T, Tani S, Wakagi T, et al. Crystal structures of glycoside hydrolase family 3 beta-glucosidase 1 from Aspergillus aculeatus. Biochem J. 2013;452:211-21.

19. Pozzo T, Pasten JL, Karlsson EN, Logan DT. Structural and functional analyses of beta-glucosidase 3B from Thermotoga neapolitana: a thermostable three-domain representative of glycoside hydrolase 3. J Mol Biol. 2010;397:724-39.

20. Birch PRJ, Sims PFG, Broda P. Substrate-dependent differential splicing of introns in the regions encoding the cellulose-binding domains of 2 exo-cellobiohydrolase-l-like genes in Phanerochaete chrysosporium. Appl Environ Microbiol. 1995:61:3741-4.

21. Beckham GT, Bomble YJ, Matthews JF, Taylor C, Resch MG, Yarbrough JM, et al. The O-glycosylated linker from the Trichoderma reesei Family 7 cellulase is a flexible, disordered protein. Biophys J. 2010;99:3773-81.

22. Guan X, Chaffey PK, Zeng C, Greene ER, Chen L, Drake MR, et al. Molecular-scale features that govern the effects of $O$-glycosylation on a carbohydrate-binding module. Chem Sci. 2015;6:7185-9.

23. Marsh JW, Denis J, Wriston JC. Glycosylation of Escherichia-Coli L-Asparaginase. J Biol Chem. 1977;252:7678-84.

24. Sun Y, Cheng JY. Hydrolysis of lignocellulosic materials for ethanol production: a review. Biores Technol. 2002;83:1-11.

25. Bhatia Y, Mishra S, Bisaria VS. Microbial beta-glucosidases: cloning, properties, and applications. Crit Rev Biotechnol. 2002;22:375-407.

26. Wallecha A, Mishra S. Purification and characterization of two $\beta$-glucosidases from a thermo-tolerant yeast Pichia etchellsii. Biochimica et Biophysica Acta Proteins Proteom. 2003;1649:74-84.

27. Toonkool P, Metheenukul P, Sujiwattanarat P, Paiboon P, Tongtubtim N Ketudat-Cairns $M$, et al. Expression and purification of dalcochinase, a $\beta$-glucosidase from Dalbergia cochinchinensis Pierre, in yeast and bacterial hosts. Protein Expr Purif. 2006;48:195-204.

28. Hong J, Tamaki H, Kumagai H. Cloning and functional expression of thermostable $\beta$-glucosidase gene from Thermoascus aurantiacus. Appl Microbiol Biotechnol. 2007:73:1331-9.

29. Liu D, Zhang R, Yang X, Zhang Z, Song S, Miao Y, et al. Characterization of a thermostable $\beta$-glucosidase from Aspergillus fumigatus Z5, and its functional expression in Pichia pastoris X33. Microb Cell Fact. 2012;11:25.

30. Karnaouri A, Topakas E, Paschos T, Taouki I, Christakopoulos P. Cloning, expression and characterization of an ethanol tolerant $\mathrm{GH} 3 \beta$-glucosidase from Myceliophthora thermophila. Peerj. 2013;1:e46.

31. Yang X, Ma R, Shi P, Huang H, Bai Y, Wang Y, et al. Molecular characterization of a highly-active thermophilic $\beta$-glucosidase from Neosartorya fischeri P1 and its application in the hydrolysis of soybean isoflavone glycosides. PLoS ONE. 2014;9:e106785.

32. Ramani G, Meera B, Vanitha C, Rajendhran J, Gunasekaran P. Molecular cloning and expression of thermostable glucose-tolerant $\beta$-glucosidase of Penicillium funiculosum NCL1 in Pichia pastoris and its characterization. J Ind Microbiol Biotechnol. 2015;42:553-65. 
33. Pei X, Zhao J, Cai P, Sun W, Ren J, Wu Q, et al. Heterologous expression of a GH3 $\beta$-glucosidase from Neurospora crassa in Pichia pastoris with high purity and its application in the hydrolysis of soybean isoflavone glycosides. Protein Expr Purif. 2016;119:75-84.

34. Xia W, Xu X, Qian L, Shi P, Bai Y, Luo H, et al. Engineering a highly active thermophilic $\beta$-glucosidase to enhance its $\mathrm{pH}$ stability and saccharification performance. Biotechnol Biofuels. 2016;9:147.

35. Wang Y, Yuan H, Wang J, Yu Z. Truncation of the cellulose binding domain improved thermal stability of endo- $\beta-1,4$-glucanase from Bacillus subtilis JA18. Biores Technol. 2009;100:345-9.

36. Vogt G, Woell S, Argos P. Protein thermal stability, hydrogen bonds, and ion pairs1. J Mol Biol. 1997;269:631-43.

37. Notenboom V, Boraston AB, Chiu P, Freelove ACJ, Kilburn DG, Rose DR. Recognition of cello-oligosaccharides by a family 17 carbohydrate-binding module: an X-ray crystallographic, thermodynamic and mutagenic study1. J Mol Biol. 2001;314:797-806

38. Viegas A, Bras NF, Cerqueira NM, Fernandes PA, Prates JA, Fontes CM, et al. Molecular determinants of ligand specificity in family 11 carbohydrate binding modules - an NMR, X-ray crystallography and computational chemistry approach. FEBS J. 2008;275:2524-35.

39. Singhania RR, Patel AK, Sukumaran RK, Larroche C, Pandey A. Role and significance of beta-glucosidases in the hydrolysis of cellulose for bioethanol production. Biores Technol. 2013;127:500-7.

40. Jeya M, Joo AR, Lee KM, Tiwari MK, Lee KM, Kim SH, et al. Characterization of $\beta$-glucosidase from a strain of Penicillium purpurogenum KJS506. Appl Microbiol Biotechnol. 2010;86:1473-84.

41. Gusakov AV. Alternatives to Trichoderma reesei in biofuel production. Trends Biotechnol. 2011;29:419-25.

42. Mandels M, Weber J. The production of cellulases. In: Cellulases and their applications, Chapter 23. Advances in Chemistry, vol. 95. American Chemical Society, pp. 391-414.
43. Shevchenko A, Tomas H, Havlis J, Olsen JV, Mann M. In-gel digestion for mass spectrometric characterization of proteins and proteomes. Nat Protocols. 2007;1:2856-60.

44. Britton HTS, Robinson RA. CXCVIII.--Universal buffer solutions and the dissociation constant of veronal. J Chem Soc. 1931;1456-62. doi:10.1039/ JR9310001456.

45. Schwede T, Kopp J, Guex N, Peitsch MC. SWISS-MODEL: an automated protein homology-modeling server. Nucleic Acids Res. 2003;31:3381-5.

46. Delano WL. Use of PYMOL as a communications tool for molecular science. Abstr Papers Am Chem Soc. 2004;228:U313-4.

47. Nieto-Domínguez M, de Eugenio LI, Barriuso J, Prieto A, Fernández de Toro B, Canales-Mayordomo Á, et al. Novel pH-stable glycoside hydrolase family $3 \beta$-xylosidase from Talaromyces amestolkiae: an enzyme displaying regioselective transxylosylation. Appl Environ Microbiol. 2015;81:6380-92.

48. Somogyi $M$. A new reagent for the determination of sugars. J Biol Chem. 1945;160:61-8.

49. Chundawat SPS, Bellesia G, Uppugundla N, Costa Sousa L, Gao D, Cheh $A M$, et al. Restructuring the crystalline cellulose hydrogen bond network enhances its depolymerization rate. J Am Chem Soc. 2011;133:11163-74.

50. Guo B, Sato N, Biely P, Amano Y, Nozaki K. Comparison of catalytic properties of multiple $\beta$-glucosidases of Trichoderma reesei. Appl Microbiol Biotechnol. 2016;100:4959-68.

51. Uchiyama T, Miyazaki K, Yaoi K. Characterization of a novel $\beta$-glucosidase from a compost microbial metagenome with strong transglycosylation activity. J Biol Chem. 2013;288:18325-34.

52. Pei J, Pang Q, Zhao L, Fan S, Shi H. Thermoanaerobacterium thermosaccharolyticum $\beta$-glucosidase: a glucose-tolerant enzyme with high specific activity for cellobiose. Biotechnol Biofuels. 2012;5:31.

\section{Submit your next manuscript to BioMed Central and we will help you at every step:}

- We accept pre-submission inquiries

- Our selector tool helps you to find the most relevant journal

- We provide round the clock customer support

- Convenient online submission

- Thorough peer review

- Inclusion in PubMed and all major indexing services

- Maximum visibility for your research

Submit your manuscript at www.biomedcentral.com/submit 